
Kidney
Bloód Pressure
Research

Review

\title{
Interventional Decentralized Tele- monitoring: Bridging the Gap Between Patient's Device and Physician's Needs in Well Selected Indications
}

\author{
Egbert G. Schulz Claas L. Neumann \\ Nephrologisches Zentrum Göttingen GbR, Göttingen, Germany
}

\author{
Key Words \\ Hypertension • Dialysis $•$ Pregnancy $・$ Telemedicine $・$ Blood pressure $\bullet$ Body weight
}

\begin{abstract}
Telemedicine comprises different concepts aiming to close a spatial distance between practitioner, medical staff and patient. It's functionality can include mere data transmission but extend as well to triggering alarms or enable consultation and therapy suggestions. A special form of telemedicinal application is interventional decentralized telemonitoring. Here practitioner-patient communication is characterized by telemedicinial data collection driven therapy-control and -optimization. To identify feasible indications for the employment of telemonitoring a detailed definition of communicated parameters, alarm rules and algorithms of intervention are required as well as a benefit-cost analysis. The quality of the telemedical application is determined by the medical quality of the resulting actions.
\end{abstract}

Copyright (C) 2015 S. Karger AG, Basel

\section{Introduction}

Over the course of the last 20 year telemedicine introduced various concepts and methods to bridge the spatial gap between practitioner, medical service professional and patient. But most of these approaches could not make it to the width of medical care due to lack of evidence and practicality [1]. Approaches were established with focus on pure data transmission as well as alarm functionality, consultation and therapy management.

While in general, telemedical methods differ over a wide range, some recurring common patterns exist (Fig. 1). Between different approaches, most variation is found in the spatial distances and quality and quantity of communicated data. 


\section{Kidney \\ Blood Pressure Research}

\section{Kidney Blood Press Res 2015;40:130-140}

\begin{tabular}{l|l}
\hline DOI: $10.1159 / 000368489$ & (c) 2015 S. Karger AG, Basel
\end{tabular}

Published online: March 22, 2015

www.karger.com/kbr

131

Fig. 1. Different telemedical approaches and their commonalities. BC: Online/telephone consultation centre; CC: Call centre for specific parameters (e.g. INR, body weight for cardiac insufficiency); SCT: Specialised competence telemedicine (e.g. Neurological assessment for apoplexy); COT: In clinic/ office telemonitoring (e.g. cardiovascular monitoring by an intermediate care unit); iTM: Individual interventional telemonitoring (Individualised data transfer between practitioner and patient connected to individual therapy decisions).

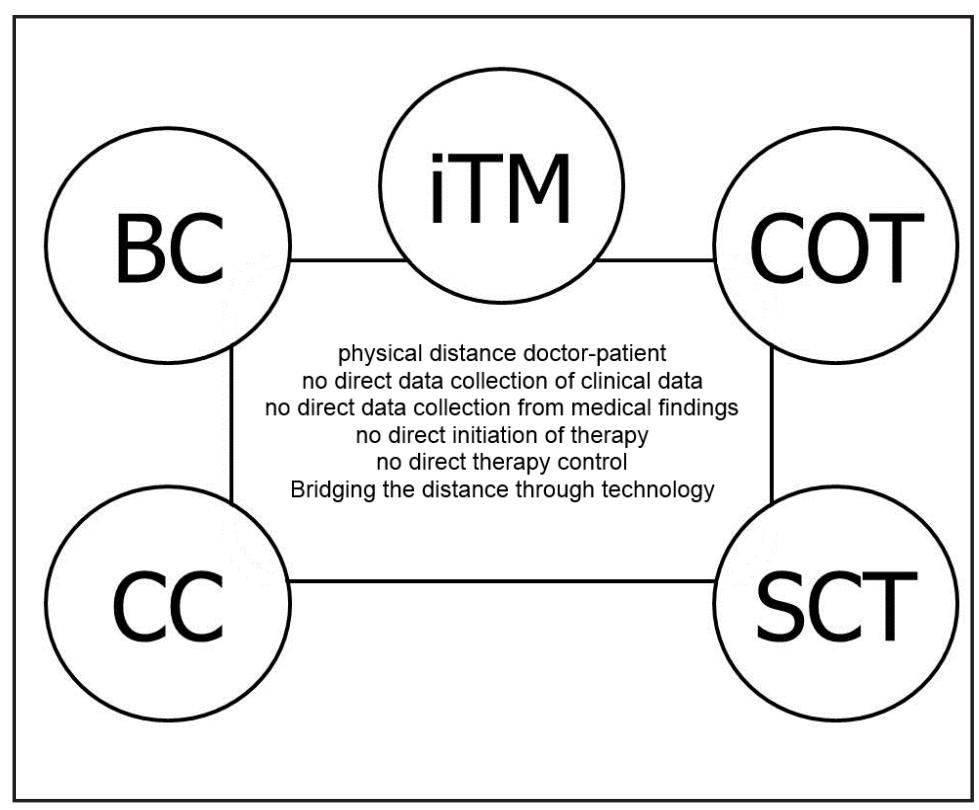

This review aims to give an overview of the capabilities of interventional decentralised telemonitoring (idTM) as an individual patient-centered tool for diagnosis and therapy focusing on blood pressure and body-weight as relevant parameters for various diseases.

The increasing demand for telemedical solutions is caused by a wealth of, in parts independent, developments [2,3]. Besides ageing societies and an increase [4,5] in chronic diseases with earlier onset [6], centralisation of medical competence and a decline in medical service coverage of rural areas [7, 8], increasing social isolation and the loss of support networks inside and outside of families $[9,10]$ as well as higher expectations to therapy standards are to name [11].

Moreover, these factors result in a higher number of visits to the general practitioner per patient contributing to the strain on resources in the health sector $[12,13]$. There exist claims that telemedicine cannot be the answer to requirements arising from an ageing demographic, as the elderly patients are challenged to operate the employed technology adequately [14]. Numerous studies have however found no indication that this is true and the argument can be dismissed [15-18].

Following the requirements of the Federal joint committee (G-BA) - as the highest decision-making body of the joint self-government of physicians, dentists, hospitals and health insurance funds in Germany - of the year 2013 for the evaluation of safety, effectiveness and necessity of the respective telemedicine application, the involved doctors need to prove understanding the disease and its context as well as provide prove of medical feasibility as well as cost efficiency of the approach.

\section{Interventional decentralised telemonitoring (idTM)}

A special form of telemedicine applications is the interventional decentralised telemonitoring in which the individual patient-practitioner situation motivates therapy management and optimisation on the basis of telemedical obtained data [19].

The success of the approach can, in addition to the need for therapy optimisation and its relevance in socio-economic context, be attributed to the practitioner providing continuous and individual supervision, who understands the context of the treated condition as well as idTM including possible resulting individual alarm conditions and consequences for therapy parameters (Tab. 1). Beyond the automated measurement, the patient does not need to take 


\section{Kidney Blood Pressure Research}

Table 1. Body weight and blood pressure telemetry reporting conditions and interventions for high risk pregnancy patients

\begin{tabular}{ll}
\hline Alarm/report thresholds & \multicolumn{1}{c}{ Intervention } \\
\hline (Measurements taken at home 07.00-09.00 a.m.) & \\
Alarm thresholds blood pressure: & \\
$\quad$ - 5-day-mean $>135 / 85 ;<100 / 60 \mathrm{mmHg}$ & \multicolumn{1}{c}{ Intervention via phone: } \\
$\quad$ - Single value $>160 / 100 ;<90 / 50 \mathrm{mmHg}$ & Well-being, edema, gynecological findings \\
$\quad-3$ consecutive days without measurement & \\
$\quad-2$,hypertension alarms“ during 3 & \\
consecutive days & \\
Alarm thresholds body weight: & \\
$>0,5 \mathrm{~kg}$ in $24 \mathrm{~h}$ & Intervention via phone (see blood pressure) \\
$>1$ kg in 3 days & Hospitalisation \\
3 consecutive days without measurement & Intervention via phone (see blood pressure) \\
\hline
\end{tabular}

action for the results to be transmitted. This is comfortable and reliable, as it enables also the elderly, not necessarily technologically versed patient to provide reliable, authentic data for the therapy to the general practitioner as well as medical service and care staff.

To identify possible indication areas, a detailed assessment and definition of transferred parameters, alarm conditions, intervention algorithms is necessary in addition to an analysis of cost efficiency [20].

\section{Technological background}

Telemonitoring describes the transmission of telemetry by means of a combination of medical technology and a mobile phone or modem. Medical technologies here are measurement devices such as scales or blood pressure monitors. The data acquired by the patient are either electronically stored and transmitted in regular intervals or transmitted immediately after a measurement has completed. In most technical approaches, the data transmission is performed by a mobile or modem set up for the task and coupled to the measurement device, e.g. via Bluetooth. The data are send to a database. Measurements are encapsuled in a proprietary protocol allowing correlation of patient, measurement device and measurement. This coordinated communication approach ensures all data arrive complete and correct with the receiver. Individually defined thresholds trigger automatic notification of the practitioner and, if applicable, the patient as well by SMS, e-mail or fax (Fig. 2 and 3).

Communicated measurements can be accessed using a web browser as well; merely an internet connection is needed. Providing authentication information, the individual practitioner gains access to all of his patient's data and is granted rights to create new patient data sets and associate of measurement devices with patients. Furthermore individual settings and alarm conditions can be defined here.

To ensure secure data transfer between the database and user, the connection is encrypted by SSL. This tap-proof connection using the https protocol is state of the art. In addition to transmission of telemedicine data, the subsequent storage and management of collected data is of great importance. Legal requirements and further reaching patient concernes need to be addressed by providing servers with definite geographical location and well defined access rights.

Regarding diagnostics and therapy, the practitioner can evaluate the data in the context of the individual patient history and initiate further actions where necessary. These may consist e.g. of contacting the patient by phone and readjusting the therapy (Fig. 3).

In the future, communication through a smartphone with application and corresponding sensor could be considered. Currently there are neither certified sensors on the market nor 


\section{Kidney Blood Pressure Research}

Fig. 2. Blood pressure development over the course of 3 months of telemetric self-measurement of blood pressure levels (TBPM) and dose titration of anntihypertensive therapy.
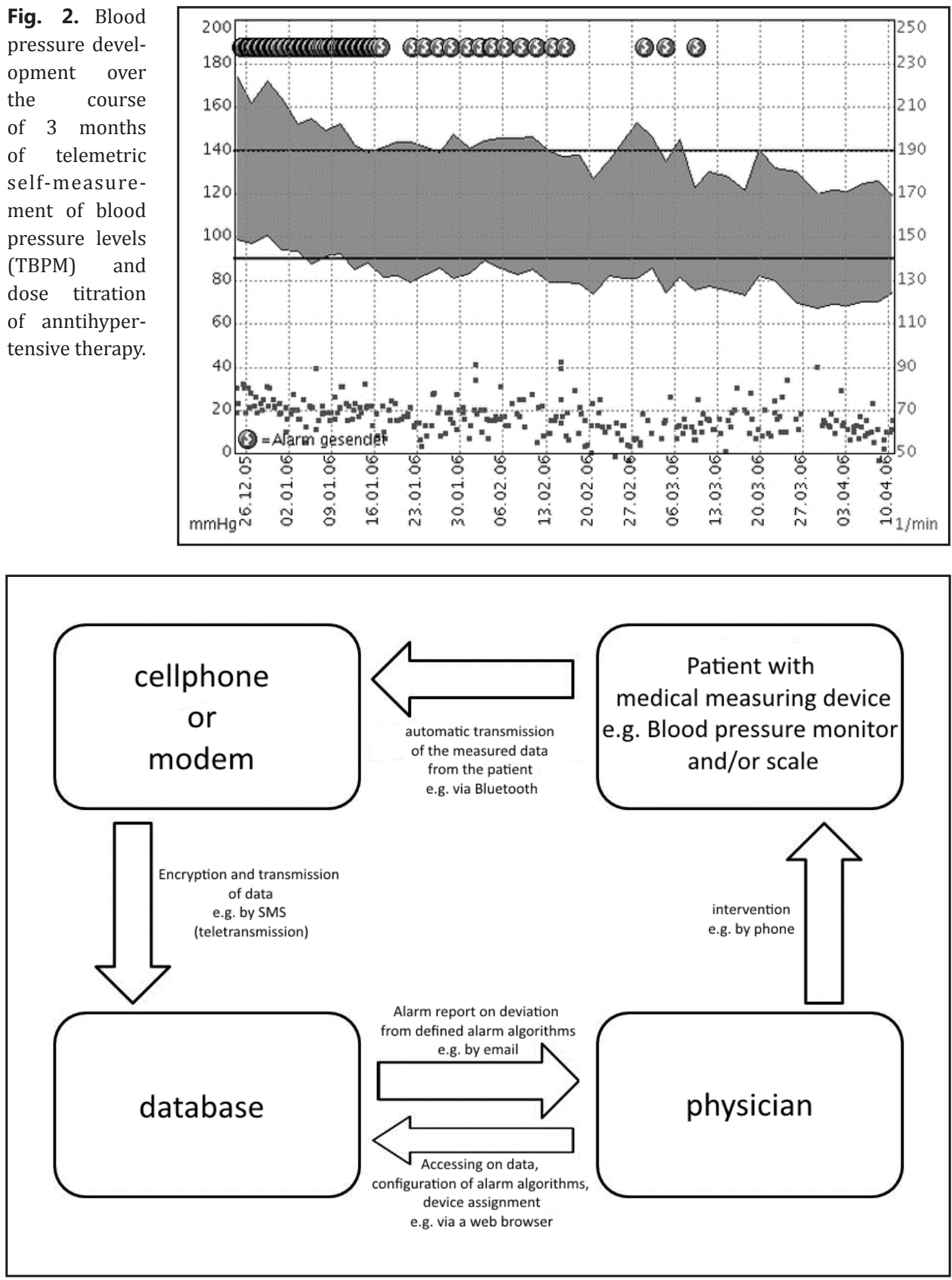

Fig. 3. Schematic of data transfer by idTM.

secure data transmission available. Applications, like Apple Healthbook (iOS 8), can currently only act as a blood pressure diary and are not recommended by the German Hypertension League (DHL) due to lack of plausibility check of documented data. 


\section{Kidney Blood Pressure Research}

Schulz/Neumann: Interventional Decentralized Telemonitoring

\section{Arterial Hypertension}

Hypertension is the leading risk factor for early death [21] with high prevalence and mortality in Europe [22]. The prevalence in men between 45 and 54 years of age in Germany lies between 40 and 70 per cent [23], in Switzerland at approximately 46 per cent [24]. Despite the fact that persisting hypertension is causing cardiovascular disease while adequate treatment is significantly reducing morbidity and mortality [25], the quality of therapy has remained static at the same level for years. Worldwide only 34 per cent of hypertension patients reach blood pressure values below 140/90 $\mathrm{mmHg}$ [26]. In Germany this number is even lower at between 10 and 25 per cent [27]. The main cause for this situation is suboptimal pharmaceutical therapy including incomplete dose titration and an insufficient number and combination of antihypertensive drugs to reach levels recommended by the the ESH/ESC guidelines. At the same time, especially with patients at high vascular risks like diabetics and patients with renal insufficiency antihypertensive over-medication has to be avoided as well [28].

To reach the goals of therapy outlined above, frequent (every 2 weeks) visits to the practice are recommended during the medication titration phase [29]. The resulting time constraints in the patient practitioner contact reduce quality of treatment, adherence to medication, persistency and compliance [30].

Blood pressure values in the morning are strongly correlated with cerebrovascular events [31,32]. The American Heart Association is therefor suggesting an observation regime comprising two measurements in the morning and in the evening, respectively [33].

Studies document that data recorded by the patient do differ from automatic measurements stored in blood pressure monitoring devices [34, 35]. Moreover the doctor cannot directly relate these data to side effects like symptomatic hypo- or hypertension reported by the patient, e.g. on the phone which might lead to wrong therapy decisions.

In this light, the remote observation by means of telemetrical blood pressure monitoring (TBPM) in particular intervententional decentralized telemetrical blood pressure monitoring (idTBPM) [36] or similar approaches seem to be a good way to enable early assessment of the patient reaction to the respective antihypertensive medication. idTBPM strengthens trust and confidence of the practitioner in the process of individual medication titration and serves to improve the adherence to medication of the patient. Especially idTBPM of blood pressure in the morning is having an important role in the prevention of hypertension events as only meaningful data here can document the necessity to lower the blood pressure during the night and in the early morning by additional antihypertensive medication late in the evening [37].

The feasibility of the approach for use in practice has been proven by a study on former inadequately treated hypertension patients [36]. In a randomised setup, 60 patients received in addition to their existing medication Irbesartan in a dose of up to 600 mg daily, taking in to consideration either only an initial ABPM measurement or additional telemetric measurements over the course of three months. Patients under telemetric observation (Fig. 1) exhibited a more pronounced reduction of systolic blood pressure $(-15.8 \mathrm{mmHg}$ compared to $-8.1 \mathrm{mmHg}$ in the control group) in an ABPM measurement commenced after 3 month at the end of the study. The significantly better reduction of blood pressure can be explained by adequate dose titration including an additional dose of the Angiotensin receptor antagonist late in the evening. Furthermore, a long term follow-up study showed a long lasting impact of the telemedical intervention, having an effect for on average 20 months [38]. Amongst other things, the cost effect balance of the method is currently subject of the study EDIMED. Here, first analyses suggest safety of the method and the feasibility of its implementation in practice $[39,40]$. 


\section{Kidney Blood Pressure Research}

Kidney Blood Press Res 2015;40:130-140

DOI: $10.1159 / 000368489$

Published online: March 22, 2015

(C) 2015 S. Karger AG, Basel

www.karger.com/kbr

Schulz/Neumann: Interventional Decentralized Telemonitoring

\section{Hemodialysis - Interdialytic weight gain and arterial hypertension}

Neither blood pressure measurements during dialysis sessions, nor ambulant $24 \mathrm{~h}$ blood pressure monitoring are reflecting the actual blood pressure dynamics of dialysis patients accurately. This is especially problematic in the context of the very narrow desired blood pressure range for these high risk patients.

The most reported symptom in patients receiving chronic hemodialysis is tantalising thirst. This fact leads to widespread non-compliance with liquid intake quotas (74 per cent of all hemodialysis patients) resulting in chronic hypervolemia and following therapy resistant hypertension, left ventricular hypertrophy, cardiac insufficiency and pulmonary complications [41].

These factors combined with extended hypotensive episodes during and after dialysis caused by the necessary high fluid removal rate associated with high ultrafiltration rates per hour lead to increased mortality and a larger number of vascular complications [42].

As psychological and pedagogical interventions do not help to improve compliance with liquid intake quotas [43], telemetrical body weight monitoring (TBWM) is a promising approach to reduce the daily fluid intake and thereby the interdialytic weight gain (IWG) of these patients.

In combination with telemetric blood pressure monitoring (TBPM) a new strategy for individual antihypertensive therapy of this specific patient type might be devised (s.a.).

After 3 months of body weight telemetry, the IWG in the second week interval (e.g. Wednesday to Friday) as well as the average weekly IWG were significantly reduced as compared to controls. Required ultrafiltration rate and systolic blood pressure at the start of dialysis were reduced, while there was a tendency of a rise in diastolic blood pressure after 3 months of TBPM [44].

\section{Hypertension during pregnancy}

During the first half of pregnancy, physiological changes introduce a slight decrease in blood pressure exhibiting a valley between the 16th and 20th week of pregnancy due to a reduction in systemic vascular resistance [45]. With respect to $24 \mathrm{~h}$ monitoring, this phase is characterised by a strong reduction over night [46], which vanishes starting from week 22nd Here, the norm level of 140/90 mmHg should however be not exceeded [47]. In about 10 per cent of pregnancies, during the last third so called hypertension of pregnancy occurs, designated by an increase of systolic blood pressure above $140 \mathrm{mmHg}$ and/or diastolic blood pressure above $90 \mathrm{mmHg}$ [47].

The telemetric monitoring and attendance of the patients can help to reduce or shorten hospitalisations for monitoring, blood pressure management and avoidance of complications [48], while as well provide indication for hospital treatment in good time, as a rise in blood pressure is the most important criterium for the diagnosis of a pre-eclamptic condition. Rises of $30 \mathrm{mmHg}$ systolic or $15 \mathrm{mmHg}$ diastolic are dangerous. In younger women having their first child and presenting blood pressure values between 100-110/60-70 mmHg in the second trimenon however, a blood pressure of 130/80 already indicates a significant increase or "relative" hypertension. Here, lacking night reduction in blood pressure is the condition crucial to diagnosis $[46,49]$. It can be reliably diagnosed by a self-measurement in the early morning [32].

\section{Hypertension related complications during pregnancy}

After the 20th week of pregnancy the pregnancy specific forms of hypertension often occur, characterised by hypertension and proteinuria, pre-eclampsia and superimposed 


\section{Kidney \\ Blood Pressure Research}

pre-eclampsia and their most severe forms, eclampsia and HELLP syndrome are the most dangerous diseases in which pathogenesis general vascular (endothelial) dysfunction is of importance [50]. Patients at risk therefor require very close and reliable monitoring of blood pressure and body weight as it can be provided by idTM.

Hypertension related complications during pregnancy occur in about 5 to 10 per cent of all pregnancies [51]. They are among the leading causes for maternal and perinatal mortality [52]. The relation of perinatal mortality and blood pressure is u-shaped [53] in that not only too high, but also too low blood pressure values introduce the risk of perinatal mortality and threaten the healthy development of the child $[53,54]$.

If hypertensive values are registered by self-monitoring, an additional ambulant $24 \mathrm{~h}$ measurement (ABPM) is indicated, to exclude possible circadian blood pressure rhythmicity [55] common in pre-eclamptic conditions, severe forms and risk patients as sporadically recorded blood pressure values in the morning or over the course of the day do not adequatly reflect the risk in the context of preeclampsia.

Hypertension, proteinuria and formation of edama are the main symptoms of preeclampsia [56]. Daily measurement of body weight by means of the "telemetric" scale is already implemented in practice for high risk pregnancies and helps to hospitalise the patients not unnecessarily but in good time (Fig. 1). Outcome studies on this are however still pending.

\section{Antihypertensive therapy during pregnancy}

Meta analyses suggest positive effects of antihypertensive therapy during pregnancy for the mother, but rather negative impact on the newborn [57] with rarely occurring severe hypertension under antihypertensive medication in mild to intermediate cases of hypertension as well as reduced birth weight and increased cases of growth retardation [58].

This explains the cautious approach to antihypertensive medication therapy for pregnant women exhibiting mild to intermediate hypertension, where non-medication measures like reduced physical activity or a temporary break from work are favoured. There is a consensus with respect to restricting therapy by medication to cases of severe hypertension only, i.e. in cases of blood pressure exceeding 170/110 mmHg or toxemia of pregnancy respectively [59].

This makes close and reliable, meaningful blood pressure monitoring even more important in order to correctly time a possibly necessary early induction of labour as well as to identify antihypertensive over-medication (Fig. 1). Thus, TBPM is very well suited for therapy management in the outpatient sector.

\section{Conclusion}

Blood pressure monitoring for arterial hypertension

TBPM is effective and first results on its cost efficiency confirm it as a feasible method for the optimisation of blood pressure monitoring.

Body weight and blood pressure monitoring in hemodialysis patients

TBWM is an effective method to optimise IWG as well as to reduce ultrafiltration rates and diastolic blood pressure levels in hemodialysis patients. Hospitalisation and diastolic hypotension during dialysis can be avoided. In combination with TBPM a possible antihypertensive therapy which is adjusted to the weekly dialysis rhythm and the resulting variations in volume status is conceivable. Long term studies on the duration of effects on IWG and mortality and hospitalisation rates are pending. Based on the results of the ongoing EDIMED study, these would allow for a cost efficiency analysis. A first data analysis already 


\section{Kidney \\ Blood Pressure Research}

shows a lower time spent on processes in the doctor's office compared to standard treatment of hypertension. A final data analysis is done currently.

\section{Body weight and blood pressure monitoring in pregnant patients}

The dynamics of blood pressure levels and body weight are two very important parameters for the course of a pregnancy. Both too low as well as too high blood pressure levels can have negative effects on the development of the fetus. Too high weight gain poses a risk even without hypertension.

Telemetry methods enable the daily transfer of blood pressure and weight data to the medical practice and thus short response times. Developing risks can be recognised early and possible complications effectively counteracted. Therefor TBWM and TBPM may prove to be an effective method to prevent hypertension related complications during high risk pregnancies. Here randomised outcome studies are still required.

\section{Interventional decentralised telemonitoring (idTM)}

IdTM is providing the practitioner with a tool for the optimal monitoring and therapy management of her or his patients. The transferred parameters and alarm algorithms are here dependent on the indications for which evidence of effectiveness of telemetrical methods has been provided to different extend. The amplification of the existing practitioner patient relationship, the avoidance of vast data volumes by well defined alarm criteria as well as its limited runtime and immediate impact on therapy decisions set idTM apart from other telemedical applications dominated by centralised approaches.

For further investigation of functionality and use of ITBPM a study register (EUSTAR - European Society of Hypertension Arterial hypertension in Telemedicine Register) was established under the auspices of the European Society of Hypertension (ESH). In this register will now examine these special indications described above with detailed definition of communicated parameters, alarm rules and algorithms of intervention for in the width of the ESH Hypertension Excellence Centers.

The following indications are planned in form of sub-registers: hypertension, hypertension in children and adolescents, pregnancy hypertension, dialysis, post-transplant, post-intervention, post-stroke and chronic heart failure. The start of the registry is scheduled for mid 2015 and is currently in detailed elaboration.

Not least now must be noted - the quality of a telemedical method can be related to the quality of the medical decisions derived from its application, making intensive training in institutions employing idTM by doctors specialised in the respective area of indication, indispensable.

\section{Abbreviations}

idTM: interventional decentralised Telemonitoring; SMS: Short Message Service; SSL: Secure Sockets Layer; HTTPS: Hypertext Transfer Protocol Secure; ESH: European Society of Hypertension; ESC: European Society of Cardiology; TBPM: Telemetric blood pressure monitoring; ABDM: Ambulant Blood pressure Monitoring; TBWM: Telemetric body weight monitoring; IWG: Interdialytic weight gain.

\section{Disclosure Statement}

The authors of this manuscript state that they do not have any conflict of interests and nothing to disclose. 


\section{Kidney \\ Blood Pressure Research}

Kidney Blood Press Res 2015;40:130-140

\begin{tabular}{l|l}
\hline DOI: $10.1159 / 000368489$ & (c) 2015 S. Karger AG, Basel
\end{tabular}

Published online: March 22, 2015

www.karger.com/kbr

\section{References}

1 Wootton R: Twenty years of telemedicine in chronic disease management--an evidence synthesis. J Telemed Telecare 2012;18:211-220.

2 Louis AA, Turner T, Gretton M, Baksh A, Cleland JG: A systematic review of telemonitoring for the management of heart failure. Eur J Heart Fail 2003;5:583-590.

3 Chaudhry SI, Phillips CO, Stewart SS, Riegel B, Mattera JA, Jerant AF, Krumholz HM: Telemonitoring for patients with chronic heart failure: a systematic review. J Card Fail 2007;13:56-62.

4 Moulias R, Hajem S: [Geriatrics and sustainable development]. Soins Gerontol 2013;22-26.

5 Peters E, Pritzkuleit R, Beske F, Katalinic A: [Demographic change and disease rates: a projection until 2050]. Bundesgesundheitsblatt Gesundheitsforschung Gesundheitsschutz 2010;53:417-426.

6 Lozano R, Naghavi M, Foreman K, Lim S, Shibuya K, Aboyans V, Abraham J, Adair T, Aggarwal R, Ahn SY, Alvarado M, Anderson HR, Anderson LM, Andrews KG, Atkinson C, et al. : Global and regional mortality from 235 causes of death for 20 age groups in 1990 and 2010: a systematic analysis for the Global Burden of Disease Study 2010. Lancet 2012;380:2095-2128.

7 Kopetsch T: The medical profession in Germany: past trends, current state and future prospects. Cah Sociol Demogr Med 2004;44:43-70.

8 Beck D, Elkeles T: [Health and life satisfaction in north-east German rural communities in 1973, 1994 and 2004/08]. Gesundheitswesen 2012;74:132-138.

9 Hundertmark-Mayser J: [An overview of self-help structures in Germany]. Z Arztl Fortbild Qualitatssich 2005;99:607-612.

10 Chasek P, Goree LJt: International Conference on Population and Development: year-end update. Earth Negot Bull 1993;6:1-4.

11 Schneider N: Health care in seniority: crucial questions and challenges from the perspective of health services research. Z Gerontol Geriatr 2006;39:331-335.

12 Thomas A: [Barmer GEK Report: Always more patient contacts. Revolving door medicine in the general practice?]. MMW Fortschr Med 2010;152:10.

13 Gaikwad R, Warren J: The role of home-based information and communications technology interventions in chronic disease management: a systematic literature review. Health Informatics J 2009;15:122-146.

14 Pare G, Jaana M, Sicotte C: Systematic review of home telemonitoring for chronic diseases: the evidence base. J Am Med Inform Assoc 2007;14:269-277.

15 Kerry SM, Markus HS, Khong TK, Cloud GC, Tulloch J, Coster D, Ibison J, Oakeshott P: Home blood pressure monitoring with nurse-led telephone support among patients with hypertension and a history of stroke: a community-based randomized controlled trial. CMAJ 2013;185:23-31.

16 Pedone C, Chiurco D, Scarlata S, Incalzi RA: Efficacy of multiparametric telemonitoring on respiratory outcomes in elderly people with COPD: a randomized controlled trial. BMC Health Serv Res 2013;13:82.

17 Prieto-Guerrero A, Mailhes C, Castanie F: OURSES: a telemedicine project for rural areas in france. Telemonitoring of elderly people. Conf Proc IEEE Eng Med Biol Soc 2008;2008:5855-5858.

18 AbuDagga A, Resnick HE, Alwan M: Impact of blood pressure telemonitoring on hypertension outcomes: a literature review. Telemed J E Health 2010;16:830-838.

19 Parati G, Stergiou GS, Asmar R, Bilo G, de Leeuw P, Imai Y, Kario K, Lurbe E, Manolis A, Mengden T, O'Brien E, Ohkubo T, Padfield P, Palatini P, Pickering T, Redon J, Revera M, Ruilope LM, Shennan A, Staessen JA, Tisler A, Waeber B, Zanchetti A, Mancia G: European Society of Hypertension guidelines for blood pressure monitoring at home: a summary report of the Second International Consensus Conference on Home Blood Pressure Monitoring. J Hypertens 2008;26:1505-1526.

20 Pare G, Moqadem K, Pineau G, St-Hilaire C: Clinical effects of home telemonitoring in the context of diabetes, asthma, heart failure and hypertension: a systematic review. J Med Internet Res 2010;12:e21.

21 Lopez AD, Mathers CD, Ezzati M, Jamison DT, Murray CJ: Global and regional burden of disease and risk factors, 2001: systematic analysis of population health data. Lancet 2006;367:1747-1757.

22 Wolf-Maier K, Cooper RS, Banegas JR, Giampaoli S, Hense HW, Joffres M, Kastarinen M, Poulter N, Primatesta P, Rodriguez-Artalejo F, Stegmayr B, Thamm M, Tuomilehto J, Vanuzzo D, Vescio F: Hypertension prevalence and blood pressure levels in 6 European countries, Canada, and the United States. Jama 2003;289:2363-2369. 


\section{Kidney \\ Blood Pressure Research}

\section{Kidney Blood Press Res 2015;40:130-140}

DOI: 10.1159/000368489

Published online: March 22, 2015

Schulz/Neumann: Interventional Decentralized Telemonitoring

23 Meisinger C, Heier M, Volzke H, Lowel H, Mitusch R, Hense HW, Ludemann J: Regional disparities of hypertension prevalence and management within Germany. J Hypertens 2006;24:293-299.

24 Danon-Hersch N, Marques-Vidal P, Bovet P, Chiolero A, Paccaud F, Pecoud A, Hayoz D, Mooser V, Waeber G, Vollenweider P: Prevalence, awareness, treatment and control of high blood pressure in a Swiss city general population: the CoLaus study. Eur J Cardiovasc Prev Rehabil 2009;16:66-72.

25 Mensah GA: The global burden of hypertension: good news and bad news. Cardiol Clin 2002;20:181-185.

26 Erdine S, Aran SN: Current status of hypertension control around the world. Clin Exp Hypertens 2004;26:731-738.

27 Yakovlevitch M, Black HR: Resistant hypertension in a tertiary care clinic. Arch Intern Med 1991;151:17861792.

28 Taylor J: 2013 ESH/ESC guidelines for the management of arterial hypertension. Eur Heart J 2013;34:21082109.

29 Mancia G, Fagard R, Narkiewicz K, Redon J, Zanchetti A, Bohm M, Christiaens T, Cifkova R, De Backer G, Dominiczak A, Galderisi M, Grobbee DE, Jaarsma T, Kirchhof P, Kjeldsen SE, Laurent S, Manolis AJ, Nilsson PM, Ruilope LM, Schmieder RE, Sirnes PA, Sleight P, Viigimaa M, Waeber B, Zannad F: 2013 ESH/ESC Guidelines for the management of arterial hypertension: the Task Force for the management of arterial hypertension of the European Society of Hypertension (ESH) and of the European Society of Cardiology (ESC). J Hypertens 2013;31:1281-1357.

30 Hobbs FD, Erhardt L: Acceptance of guideline recommendations and perceived implementation of coronary heart disease prevention among primary care physicians in five European countries: the Reassessing European Attitudes about Cardiovascular Treatment (REACT) survey. Fam Pract 2002;19:596-604.

31 Bursztyn M: Morning blood pressure surge and the risk of stroke. Circulation 2003;108:e110-111; author reply e110-111.

32 Kaplan NM: Morning surge in blood pressure. Circulation 2003;107:1347.

33 Pickering TG, Miller NH, Ogedegbe G, Krakoff LR, Artinian NT, Goff D: Call to action on use and reimbursement for home blood pressure monitoring: Executive Summary. A joint scientific statement from the American Heart Association, American Society of Hypertension, and Preventive Cardiovascular Nurses Association. J Clin Hypertens (Greenwich) 2008;10:467-476.

34 Stergiou G, Mengden T, Padfield PL, Parati G, O'Brien E: Self monitoring of blood pressure at home. BMJ 2004;329:870-871.

35 Nuesch R, Schroeder K, Dieterle T, Martina B, Battegay E: Relation between insufficient response to antihypertensive treatment and poor compliance with treatment: a prospective case-control study. BMJ 2001;323:142-146.

36 Neumann CL, Menne J, Rieken EM, Fischer N, Weber MH, Haller H, Schulz EG: Blood pressure telemonitoring is useful to achieve blood pressure control in inadequately treated patients with arterial hypertension. J Hum Hypertens 2011;25:732-738.

37 Staessen JA, Thijs L, Fagard R, O'Brien ET, Clement D, de Leeuw PW, Mancia G, Nachev C, Palatini P, Parati G, Tuomilehto J, Webster J: Predicting cardiovascular risk using conventional vs ambulatory blood pressure in older patients with systolic hypertension. Systolic Hypertension in Europe Trial Investigators. JAMA 1999;282:539-546.

38 Neumann CL, Rieken EM, Schmidt Thrun JM, Schulz EG: Long- term effects of 3 months blood pressure telemonitoring in inadequately treated patients with hypertension. The Journal of Clinical Hypertension 2011;Volume 13, Issue P0-293; A. 133.

39 Drees A, Langkau T, Leppert F, Peters C, Soltani N, Gök M, Menschner P, Greiner W, Kolbe L, Leimeister JM, Möller K, Rienhoff O: Nutzung von Prozessreferenzmodellen zur Produktivitätsmessung und -steigerung von Dienstleistungen - Konzepte und Umsetzung am Beispiel der Effizienzbewertung telemedizinischer Dienstleistungen. Controlling - Zeitschrift für erfolgsorientierte Unternehmenssteuerung 2011;10:514520.

40 Peters C, Drees A, Leppert F, Menschner P, Leimeister JM, Möller K, Greiner W: Productivity of telemedical services - a state of the art analysis of input and output factors: 21 International RESER Conference (RESER). Hamburg, Germany, 2011. 


\section{Kidney \\ Blood Pressure Research}

\section{Kidney Blood Press Res 2015;40:130-140}

DOI: 10.1159/000368489

Published online: March 22, 2015

(C) 2015 S. Karger AG, Basel

www.karger.com/kbr

Schulz/Neumann: Interventional Decentralized Telemonitoring

41 Kugler C, Vlaminck H, Haverich A, Maes B: Nonadherence with diet and fluid restrictions among adults having hemodialysis. J Nurs Scholarsh 2005;37:25-29.

42 Stegmayr BG, Brannstrom M, Bucht S, Dimeny E, Ekspong A, Granroth B, Grontoft KC, Hadimeri H, Holmberg B, Ingman B, Isaksson B, Johansson G, Lindberger K, Lundberg L, Lundstrom O, Mikaelsson L, Mortzell M, Olausson E, Persson B, Svensson L, Wikdahl AM: Minimized weight gain between hemodialysis contributes to a reduced risk of death. Int J Artif Organs 2006;29:675-680.

43 Sharp J, Wild MR, Gumley AI: A systematic review of psychological interventions for the treatment of nonadherence to fluid-intake restrictions in people receiving hemodialysis. Am J Kidney Dis 2005;45:1527.

44 Neumann CL, Wagner F, Menne J, Brockes C, Schmidt-Weitmann S, Rieken EM, Schettler V, Hagenah GC, Matzath S, Zimmerli L, Haller H, Schulz EG: Body weight telemetry is useful to reduce interdialytic weight gain in patients with end-stage renal failure on hemodialysis. Telemed J E Health 2013;19:480-486.

45 Reiss RE, O'Shaughnessy RW, Quilligan TJ, Zuspan FP: Retrospective comparison of blood pressure course during preeclamptic and matched control pregnancies. Am J Obstet Gynecol 1987;156:894-898.

46 Ruschitzka F, Schulz E, Kling H, Schrader J, Rath W: [Longitudinal study of 24-hour blood pressure behavior in pregnancy and puerperium in patients with normal pregnancy, pre-eclampsia and HELLP syndrome]. Z Geburtshilfe Neonatol 1996;200:100-103.

47 Lenfant C: Working group report on high blood pressure in pregnancy. J Clin Hypertens (Greenwich) 2001;3:75-88.

48 Barton JR, Istwan NB, Rhea D, Collins A, Stanziano GJ: Cost-savings analysis of an outpatient management program for women with pregnancy-related hypertensive conditions. Dis Manag 2006;9:236-241.

49 Schulz E, Ruschitzka F, Rath W, Guhlke U, Schrader J: Circadian blood pressure profile in normotensive pregnancy. Nieren- und Hochdruckkrankheiten 1994;23:238-239.

50 Roberts JM, Cooper DW: Pathogenesis and genetics of pre-eclampsia. Lancet 2001;357:53-56.

51 Faridi A, Rath W: [Hypertensive illnesses in pregnancy: when is ambulatory management possible, when is hospitalization indicated?]. Zentralbl Gynakol 1999;121:608-610.

52 Deak TM, Moskovitz JB: Hypertension and pregnancy. Emerg Med Clin North Am 2012;30:903-917.

53 Steer PJ, Little MP, Kold-Jensen T, Chapple J, Elliott P: Maternal blood pressure in pregnancy, birth weight, and perinatal mortality in first births: prospective study. BMJ 2004;329:1312.

54 von Dadelszen P, Magee LA: Fall in mean arterial pressure and fetal growth restriction in pregnancy hypertension: an updated metaregression analysis. J Obstet Gynaecol Can 2002;24:941-945.

55 Brown MA, Robinson A, Bowyer L, Buddle ML, Martin A, Hargood JL, Cario GM: Ambulatory blood pressure monitoring in pregnancy: what is normal? Am J Obstet Gynecol 1998;178:836-842.

56 Davey DA, MacGillivray I: The classification and definition of the hypertensive disorders of pregnancy. Am J Obstet Gynecol 1988;158:892-898.

57 Brown MA, Whitworth JA: Management of hypertension in pregnancy. Clin Exp Hypertens 1999;21:907916.

58 von Dadelszen P, Ornstein MP, Bull SB, Logan AG, Koren G, Magee LA: Fall in mean arterial pressure and fetal growth restriction in pregnancy hypertension: a meta-analysis. Lancet 2000;355:87-92.

59 Redman CW: Fetal outcome in trial of antihypertensive treatment in pregnancy. Lancet 1976;2:753-756. 